http://jmscr.igmpublication.org/home/

ISSN (e)-2347-176x ISSN (p) 2455-0450

crossref DOI: https://dx.doi.org/10.18535/jmscr/v8i2.28

\title{
Significance of C- Reactive Protein in Diagnosis of Acute Appendicitis
}

\author{
Authors \\ Guduru Sumanth', T. Mohan Vijay Kumar², T. Dheeraj ${ }^{3}$, \\ G. Sasi Krishna ${ }^{4}$, T.J. Prasanna Kumar ${ }^{5}$ \\ ${ }^{1,2,3,4}$ Postgraduate General Surgery \\ ${ }^{5}$ M.S (General Surgery)
}

\begin{abstract}
Background: Appendicectomy for suspected acute appendicitis is a standard procedure. The rate of negative appendicectomy remains high despite advances in investigations. This study emphasizes the value of $C$ reactive protein in patients operated for clinical suspicion of acute appendicitis

Methods: This prospective study was performed on 100 patients who presented with right lower quadrant abdominal pain and were clinically diagnosed with acute appendicitis, who was operated for acute appendicitis. Depending on the results of the examination by a surgeon, patients underwent surgery for treatment of acute appendicitis. C-RP values are compared with histopathology report. Sensitivity, specificity, was calculated.

Results: CRP was high (> $10 \mathrm{mg} / \mathrm{L})$ in 81 individuals with falsely raised in 5 patients, Sensitivity of CRP $>10 \mathrm{mg}$ is $85.39 \%$, specificity of CRP >10mg is $54.54 \%$.

Conclusion: Serum c reactive protein, when elevated, supports the surgeon's clinical diagnosis of acute appendicitis. It can be used frequently to diagnose acute appendicitis so that the complication rate and negative laparotomies can be avoided. It is advisable to observe atypical patients with serial clinical examinations and CRP tests.
\end{abstract}

\section{Introduction}

Appendix is a vermiform extension from caecum, so often called the vermiform appendix.

Appendicitis can be caused due to many reasons, and among them, the most important is obstruction of lumen.

Reginald Fitz from Boston first identified appendix as one of the most common causes of right lower quadrant pain. He coined the term appendicitis and advised early surgery.

Acute appendicitis remains the most common abdominal emergencies, demanding surgical intervention. The mortality rate has decreased since the advent of antibiotics.
Usually, the picture of appendicitis is often not classical, so the diagnostic process takes longer, thus delaying surgery, increasing the possibility of complications.

On the other hand, operation without an accurate diagnosis will lead to negative appendectomy, increasing the morbidity ${ }^{1,2}$. Even with the modern diagnostic tools, misdiagnosis of appendicitis has remained constant.

Diagnostic approaches include symptoms, physical examinations, laboratory findings, and imaging modalities like ultrasonography and computerized tomography (CT) of the abdomen. Although the ultrasound has improved the 
diagnosis of appendicitis, it is highly operator dependent.

The abdominal CT carries the risk of radiation exposure and also increases the cost of treatment ${ }^{3}$. Most surgeons tend to rely on an abdominal ultrasound followed by $\mathrm{CT}$ for objective diagnosis.

As quoted by Bailey \& Love, "Notwithstanding advances in modern radiographic imaging and diagnostic laboratory investigations, the diagnosis of appendicitis remains primarily clinical, requiring a mixture of observation, clinical acumen, and surgical science" ${ }^{4}$.

Many scoring systems have been designed for the diagnosis of acute appendicitis. Among those systems, the Alvarado system is simple to apply and efficient ${ }^{5,6}$.

The clinical assessment in diagnosing appendicitis by an experienced surgeon remains reliable and superior to either Alvarado score or C reactive protein (CRP) measurement.

Nevertheless, the Alvarado score and serum CRP measurements may be of value to the inexperienced surgeon, and a high Alvarado score and serum CRP should not beignored.

\section{Aim of the Study}

The aim of this study is to estimate the significance of $\mathrm{C}$ reactive protein values in patients who were operated with clinical suspicion of acute appendicitis.

\section{Materials and Methods}

The period of the study was two years (aug 2017to Aug 2019). A prospective comparative study was designed, 100 patients presenting with pain in the right lower quadrant of the abdomen, who after clinical examination were provisionally diagnosed to have acute appendicitis and operated for the same.

\section{Inclusion Criteria}

- All Patients who were provisionally diagnosed with acute appendicitis.

\section{Exclusion Criteria}

Patients presented with non-right lower quadrant pain and those who had been admitted to other specialties for other complaints and subsequently developed right iliac fossa pain

Collection of data

A total of 100 cases were taken for this study. After detailed examination, investigations, and treated for acute appendicitis.

Serum CRP concentrations were measured before the operation by the CRP kit. Normal CRP levels range from 0 to $10 \mathrm{mg} / \mathrm{l}$ (negative). We did not take into account preoperative serum CRP concentrations for the decision of the appendicectomy. Depending on results of the examination by a surgeon, patients underwent surgery for treatment of acute appendicitis. Operative findings and histopathological examination of appendectomy specimens established the exactdiagnosis.

C-RP values are compared with final histopathology report and sensitivity, specificity was calculated

\section{Results}

statistical analysis of observations and results of this study are presented in tabular forms and graphs

In this study, among 100 patients taken for study, there are 62 males and 38 females. This is described in the form of a pie diagram.

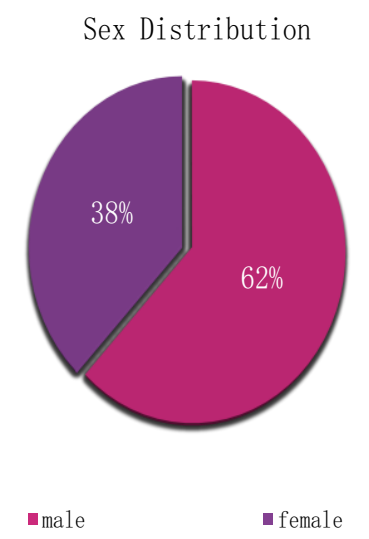

In this study, there are males (62) are more than female (38). Among male ten were less than 18 years and 52 were more than 18 years, among female 11 were less than 18 and 27 were more than 18 . 


\section{Graph 2}

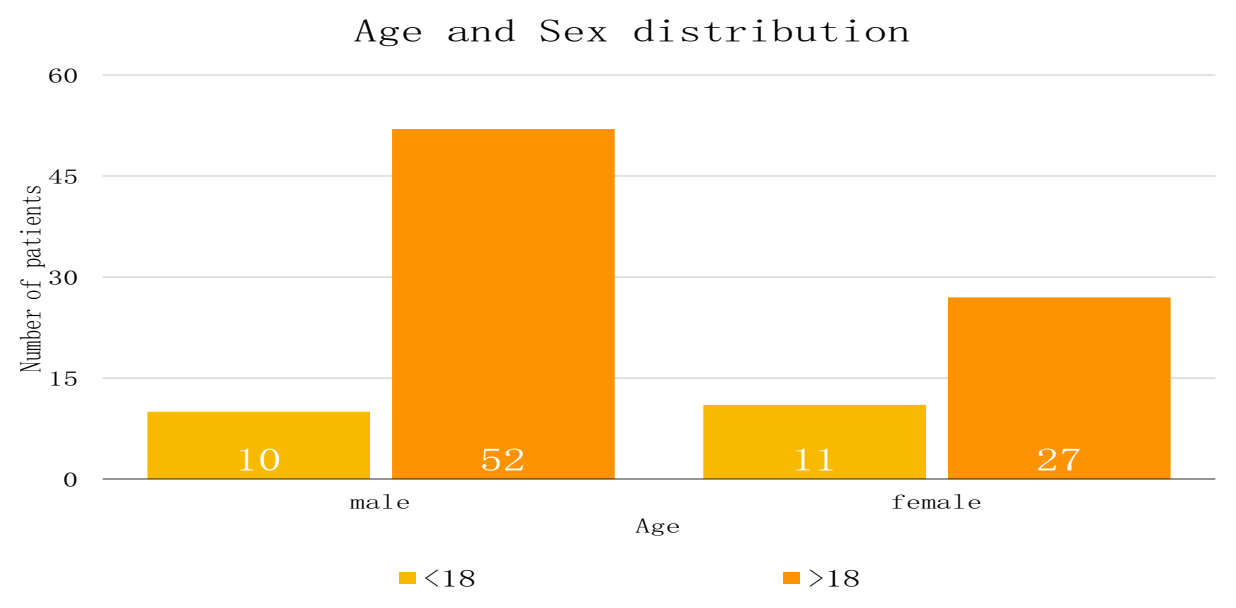

Table 1

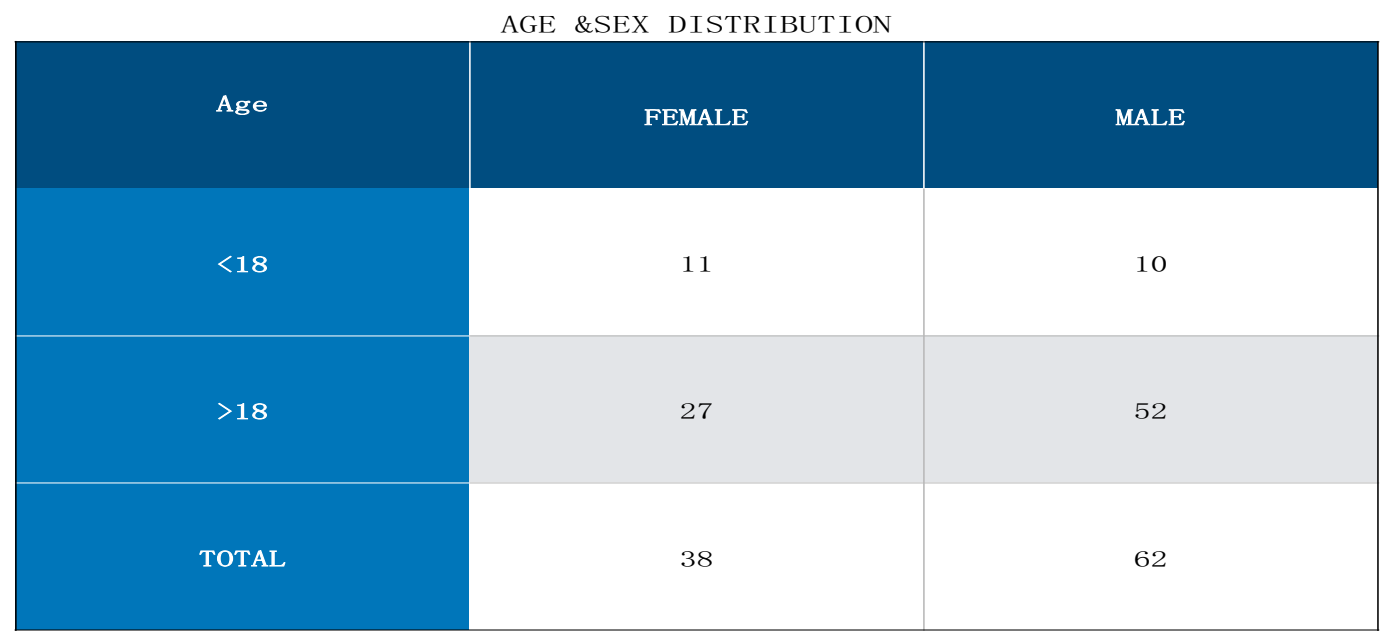

Table 2

\begin{tabular}{|c|c|c|}
\hline \multicolumn{2}{|c|}{ MEAN AGE } \\
\hline SEX & MEAN AGE \pm SD & RANGE \\
\hline Female & $28.18+14.81$ & $6-70 \mathrm{yrs}$ \\
\hline Male & $29.92 \pm 14.94$ & $12-75 \mathrm{yrs}$. \\
\hline Both & $29.22 \pm 14.91$ & $6-75 \mathrm{yrs}$. \\
\hline
\end{tabular}

- The mean age of females being $28.18+14.81$, and their age ranges between 6-70 years.

- Male mean age being 29.92+ 14.94, and their age ranges between $12-75$ years.

- Mean age of both genders being $29.22 \pm$ 14.91 and their age ranges between 675 year 


\section{Graph 8}

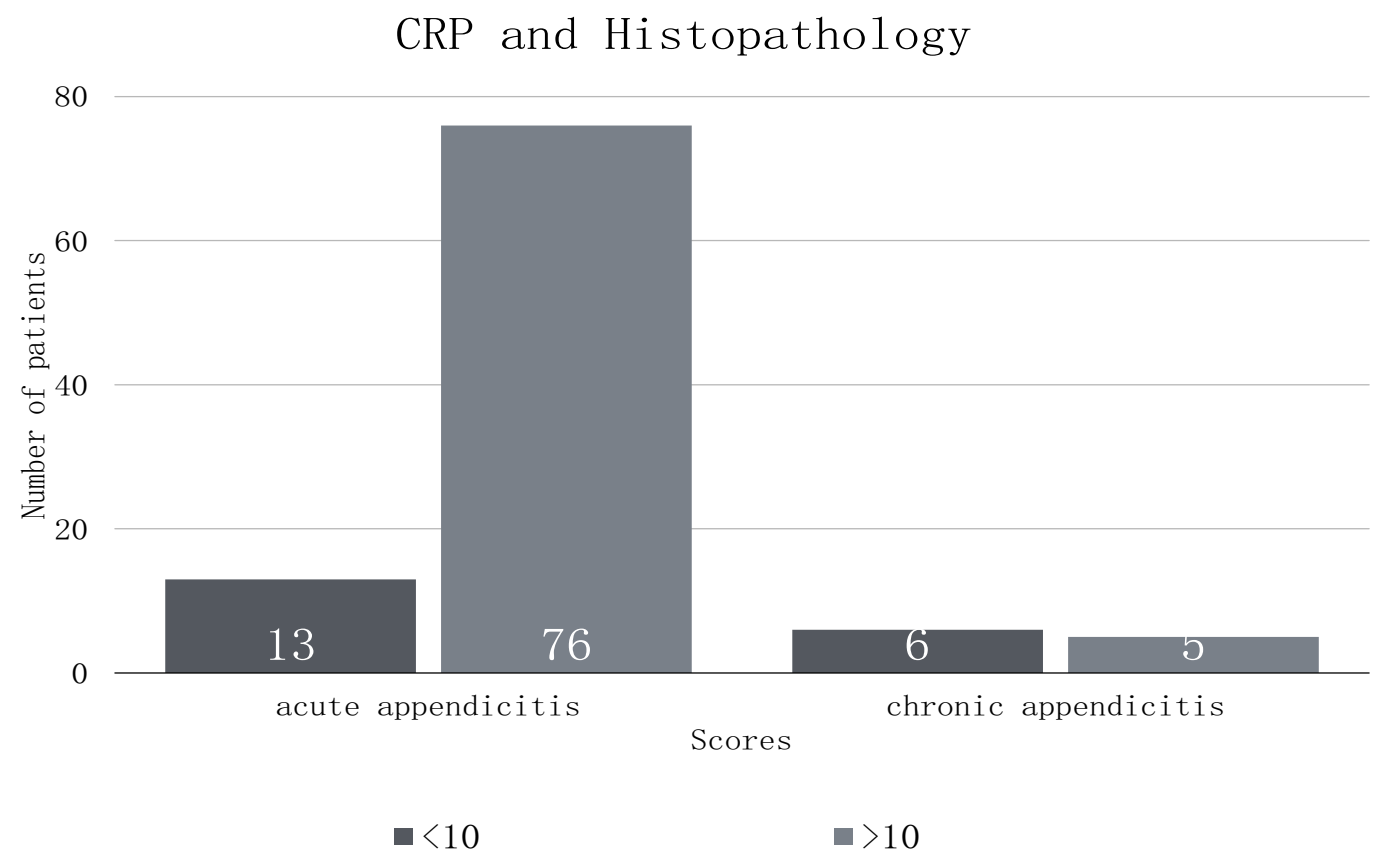

Table 8

CRP COMPARSION WITH HISTOPATHOLOGY

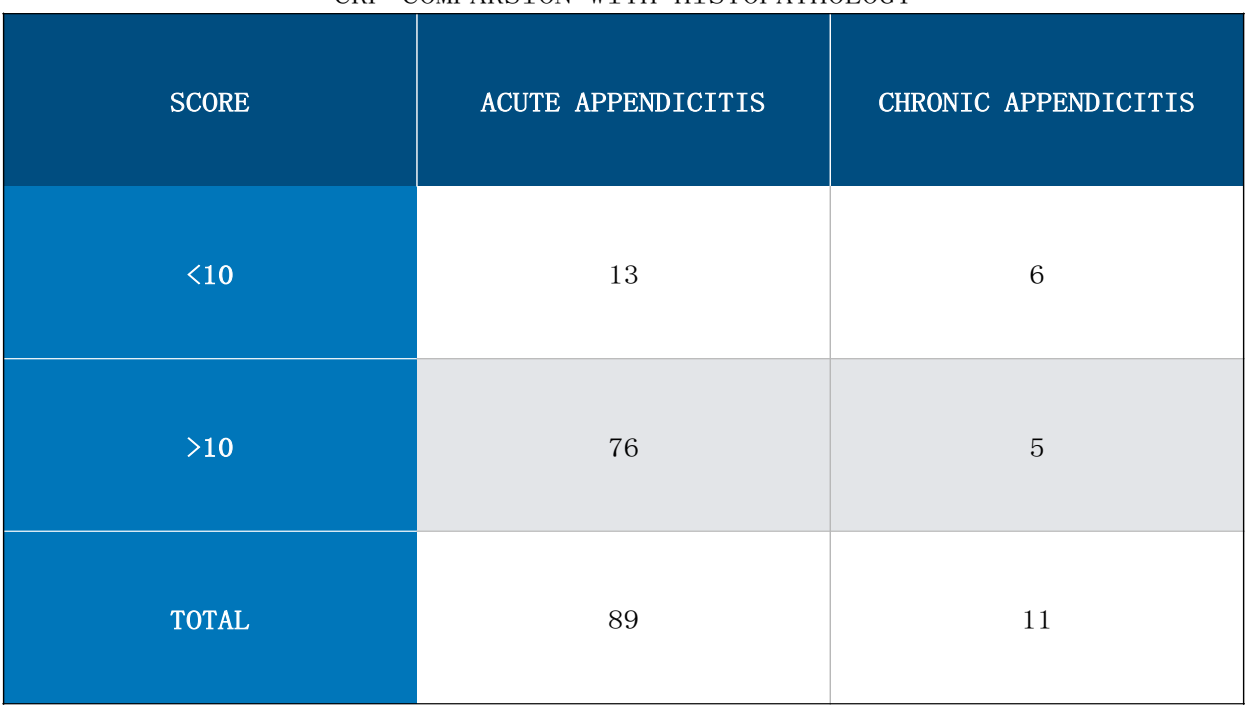

- CRP was high ( $\geq 10 \mathrm{mg} / \mathrm{L})$ in 81

Discussion individuals with falsely raised in 5 patients.

- Sensitivity of CRP $>10 \mathrm{mg}$ is $85.39 \%$.

- The specificity of CRP> $10 \mathrm{mg}$ is $54.54 \%$.

$\square$ This is a prospective study comprised of 100 patients who presented with right lower quadrant pain and were operated for the same. In this prospective study, the diagnostic value of the serum CRP levels are estimated in patients who were operated with clinical 
suspicion of acute appendicitis.

With the onset of infection, there will be an increase in the secretion of acute-phase proteins from the liver, and their

$\square$ Serum concentrations augment $8-12$ hours after the onset of infection.

CRP, is a marker of acute phase response and can be used as an indicator of disease. Elevation of serum concentrations of CRP indicates the presence of acuteappendicitis.

$\square$ In patients with acute appendicitis, the decision of surgery is based generally on the clinical impression of the surgeons.

In this study, CRP was high $(>10 \mathrm{mg} / \mathrm{l})$ in 81 individuals, and among them, five individually seemed to have falsely raised CRP.

$\square$ In this study, the sensitivity of CRP is $85.39 \%$, and specificity is $54.5 \%$.

$\square$ A recent meta-analysis showed that when both an elevated WBC count and high Creactive protein level are present, there is a fivefold increase in the positive likelihood ratio for acute appendicitis ${ }^{7}$.

So, routine performance of the CRP test can prevent negative laparotomies.

\section{Conclusion}

1) Serum C-reactive protein, when elevated, supports the surgeon's clinical diagnosis of acuteappendicitis.

2) It can be used frequently to diagnose acute appendicitis so that the complication rate and negative laparotomies can be avoided.

3) It is advisable to observe atypical patients with serial clinical examinations and CRP tests when there is doubt about the diagnosis.

\section{Summary}

- In a study of 100 patients of suspected cases of acute appendicitis, males comprised $68 \%$ and females $32 \%$.

- The mean age of females being $28.18+14.81$, and their age ranges between 6-70 years.

- Male mean age being $29.92 \pm 14.94$, and their age ranges between 12-75 years.

- Anorexia was the most common symptom followed by pain abdomen.

- Histopathology is the gold standard used in this study for confirming acute appendictis, and in this study, there are 89 cases of acute appendicitis and 11 cases of chronicappendicitis.

- In this study, CRP was high $(>10 \mathrm{mg} / \mathrm{l})$ in 81 individuals, and among them, five individually seemed to have falsely raised CRP

- In this study, the sensitivity of CRP is $85.39 \%$, and specificity is $54.5 \%$.

- USG is a safe, reliable modality for patients with acute appendicitis

\section{Bibliography}

1. Flum DR, Koepsell T. The clinical and economic correlates of misdiagnosed appendicitis: nationwide analysis. Arch Surg 2002,137(7):799-804.

2. Blomqvist PG, Andersson RE, Granath F, Lambe MP, Ekbom AR. Mortality after appendectomy in Sweden, 1987-1996. Ann Surg 2001, 233(4):455-60.

3. Hall EJ. Cancer risks from diagnostic radiology. Br J Radiol 2008, 81(965):36278.

4. Hamilton Bailey's "Emergency Surgeries", $12^{\text {th }}$ Ed, 1995;438-451

5. Alvarado A. A practical score for the early diagnosis of acuteappendicitis.AnnEmerg Med. 1986; 15:557-64.

6. Douglas CD, Macpherson NE, Davidson PM. Randomised controlled trial of ultrasonography in diagnosis of acute appendicitis, incorporating the Alvarado score. BMJ. 2000;321(7266):919-22

7. Styrud J, Eriksson S, Nilsson I et al. (2006): Appendectomy versus antibiotic treatment in acute appendicitis. a prospective multicenter randomized controlled trial. World J Surg., 30: 1033-1037. 